\title{
The regional economic impacts of offshore wind energy developments in Scotland
}

\author{
Kevin Connolly* \\ * Fraser of Allander Institute, Department of Economics, University of Strathclyde, 199 \\ Cathedral Street, Glasgow, UK, G4 0QU k.connolly@strath.ac.uk
}

Acknowledgements: This work was supported by the ESPRC under Grant [EP/G037728/1] and EPSRC SUPERGEN Wind Programme under Grant EP/L014106/1. Errors and omissions remain the responsibility of the author. I am indebted to three anonymous referees and an editor for very helpful comments on an earlier draft.

Keywords: offshore wind energy; Scotland; Input-Output; CGE modelling,

\begin{abstract}
The Scottish electricity network is currently in a transition towards becoming $100 \%$ renewable. Offshore wind, due to a large natural resource, is expected to be key in this transition. In addition to the anticipated environmental benefits, increasing the share of offshore wind is expected to bring economic benefits to the region. In this study two multi-sectoral modelling methodologies - InputOutput (IO) and Computable General Equilibrium (CGE) - are used to measure the potential economic impacts on Scotland arising from both the construction and operation of the planned increase offshore wind capacity between 2018 and 2025, with comparisons made between models and development stages. With the focus on the benefits to the Scottish economy it is important to focus only on expenditures within Scotland. Found using both 10 and (forward-looking and myopic) CGE modelling techniques, is increasing offshore wind capacity raises both employment and Gross Value Added (GVA) with the magnitude and timing of this change critically depend on model type and closure. This is the first - to the author's knowledge - of a Scottish specific modelling which helps policy makers understand those elements which could affect the possible economic success of current policy towards offshore wind.
\end{abstract}




\section{Introduction}

In recent years, reducing greenhouse gas emissions has been at the forefront of energy policy worldwide, with the promotion of renewable generation technologies being a key driver of change. There is no "one size fits all" solution and technologies which governments' have chosen to promote are wholly dependent on available natural resources. Solar and onshore wind are two prominent renewable technologies, while offshore wind has - especially in Europe - seen rapid growth in recent years [1]. Offshore wind developments, due to the nature of the resource, are usually large scale projects requiring significant investment and as such not only bring environmental benefits to a region/nation, but offer the potential for economic benefits - a key pillar of the energy quadrilemma [2].

The objective of this paper is to estimate the potential economic impacts arising from planned offshore wind developments in Scotland, with a focus on the developments which are to be operational by 2022. For these planned developments estimates of the total expenditure in Scotland, using information on planned projects and 'local content ${ }^{1}$ are developed, with this information and models then used to capture the economic impacts to Scotland. In this study two ex-ante economic methodologies - Input-Output (IO) and Computable General Equilibrium (CGE) - are employed to estimate the economic regional impacts of increasing Scottish offshore wind capacity. There is a large literature on measuring the economic impacts of renewable energy developments $[3,4]$. One stimulus to this literature has been the desire to show policy makers the link between energy development and the economy. Jenniches [5] notes that it is important to focus on regional development as - is the case with Scotland - planning decisions for renewable energy project is often taken a regional level.

This is an important contribution for a variety of reasons. Firstly, the Scottish Government has set ambitious targets (higher than those of the UK as a whole) for renewable energy and carbon reduction while claiming that this has the possibility:

"To reindustrialise Scotland through 21st century technologies and seize the opportunities to create tens of thousands of new jobs and secure billions of bounds of investment" [6].

Secondary, Scotland has one of the highest offshore wind resources in the world $-25 \%$ of all European resource [7] - and offshore wind development will be essential if Scotland is to achieve the renewable energy and carbon reduction targets. Even with this large resource, to date, the development of

\footnotetext{
${ }^{1}$ Local content is defined as the percentage of total expenditure within the region of focus (REF)
} 
Scottish offshore wind has, due to technical and environmental reasons, lagged behind the rest of the UK. There are however several projects in planning/development that will be operational by 2025 , requiring significant investment, which could have economic consequences.

Because of the importance to both energy policy and economic development there are several paper which investigate the regional economic impacts of renewable developments. Jenniches [5] reviews 54 publications from: across the UK, USA, Spain, Germany and Austria and find that regional economic impact measurement methodologies are wide varying with many papers focusing on wind and marine technologies. This review identifies 10 modelling as the predominant methodology in economic analysis.

Within a Scottish context, several papers have undertaken ex ante analysis of the possible economic impacts arising from a range of renewable technologies. Marine (wave and tidal) energy and the impact on the Scottish Economy has been the focus of two papers which use a combination of $I O$ and CGE [8][9]. Okkonen and Lehtonen [10] investigates, using an IO methodology, the regional impacts of community owned onshore wind.

Further afield, The National Renewable Energy Laboratory (NREL) has developed several "Jobs and Economic Development Impact" (JEDI) IO models to determine the economic impacts of projects within the USA, with these JEDI models able to model impacts on the different regions [11] using a range of 10 databases.

As outlined above economic modelling techniques have been used extensively in the literature to demonstrate the linkage between renewable energy developments and the economy. From the review [5], this is - to the author's knowledge - the first paper to consider the regional impacts of the construction and operation of offshore wind through both $1 O$ and CGE models. While other papers have measured the UK benefits of offshore wind [12] the focus of this paper is on only the impacts of one region of the UK (Scotland) using real local content evidence. This is important to regional policy makers as, detailed below, are part responsible in the granting of such project's thus is advantageous for regional economic benefits to be identified.

Secondly, with the difficultly of data acquisition, many studies rely on high level information on regional content to carry out macroeconomic assessments. In this study information is obtained on the Scottish content of project broken down by stage of project development (survey, turbine blades, vessels, etc.).

Finally, different modelling techniques are used in measuring the economic impacts of offshore wind in Scotland. The approach is most similar to Allan et al [8], which looks at Scottish marine energy. That 
paper focuses solely on the expenditure associated with the construction stage of projects, and finds that results produced by 10 models are always larger (than those using CGE). In this paper both the construction and operational expenditures are included. This uncovers a critical result: including spending during the operational lifetime of these projects, the economic impacts from CGE analysis (in myopic specifications) are greater than those under 10 modelling. This demonstrates the importance of looking beyond the construction period of projects in assessing economic impacts. We will explore whether this still holds when OPEX expenditures are considered.

This paper proceeds as follows. Section 2 outlines recent developments in Scottish energy policy and the support for renewables, as well as a description of wind energy in Scotland. Section 3 then outlines the expenditures associated with the development of Scottish offshore wind capacity between 2019 and 2022, and the modelling frameworks used to capture the impact on Scottish economy of those. In Section 4 results are shown and discussed while Section 5 concludes the paper and notes directions for future research.

\section{Energy policy and Scottish offshore wind energy}

Scotland is a nation within the United Kingdom however, under the 1989 Electricity (Scotland) Act, (many) electricity matters are reserved to the UK Government. Uniquely, Scottish policymakers have the ability to grant or withhold planning consent for overhead transmission lines, and generation stations over 50MW, giving the Scottish Parliament a level of autonomy in shaping a devolved energy policy [13]. With a greater level of natural resource the Scottish Government has set stricter energy targets than the UK Government. Scotland has set the target to reduce greenhouse gas emissions by $70 \%$ by 2030 [14], 13\% higher than the UK overall target for the same year. The Scottish Government has set the ambitious target of the equivalent of $100 \%$ of gross electricity consumption being generated from renewables by 2020 [15]: at the end of 2018 74.6\% of Scottish gross electricity consumption was met by renewables.

Published in 2017, through consultation with a wide range of parties, the Scottish Energy Strategy [16] sets out the Scottish Governments vision towards a low carbon society by 2050 . Within the strategy there are several futures identified, all of which note that offshore wind will play an increasingly important part.

While the Scottish Government does have some ability to shape energy policy, the support mechanisms for renewables are set by the UK Government. Since 2014, the main support mechanism for new large scale renewables (including offshore wind) has been the Contracts for Difference (CFD) scheme, seen as the direct replacement for the ROCs scheme and with the intention to decrease cost 
to consumers through lowering the cost of electricity through competition, while provided long-term financial stability to project developers. This expected reduction in cost has already been found in the offshore wind sector through each round of CfD auctions. In 2014 offshore wind farms won CfD with a price of whereas, with the most recent auction, both Moray East and East Angelia wind farms were awarded CfDs at a price of $£ 57.50 / \mathrm{MWh}[17]$.

Scotland boasts some the best wind resource (both onshore and offshore) in the world, with an estimated 11.5GW of onshore capacity potential which could deliver 45TWh of electricity per year [18]. With such as resource, and technological advancement, in the last 10 years ${ }^{2}$ onshore wind capacity has grew more than $400 \%$ with an installed capacity of $7.8 \mathrm{GW}$ [19].

Offshore wind resource in Scotland is even larger than onshore, however the growth has been much slower with a capacity of $623 \mathrm{MW}$ by the end of 2018 [19]. Scotland has been lagging behind the UK as a whole due to both technical (harsher operating environments) and environmental problems. However, as of 2018, several wind farms were "in development" outlined in Table $1^{3}$ - which are the focus of this study. The data from this table is used to inform the calculation Scottish offshore expenditures (detailed in Section 3.3).

\begin{tabular}{lcc} 
Development & Size (MW) & Completion date \\
\hline Aberdeen Bay & 100 & 2018 \\
Beatrice & 588 & 2019 \\
Inch Cape & 750 & 2021 \\
Moray East (Phase 1) & 504 & 2022 \\
Neart Na Golthe & 450 & 2022
\end{tabular}

Table 1: Offshore wind farms In Scotland [20].

\section{Models}

As noted in Jenniches [5] there are two main modelling methodologies used for examining the potential economic impacts of increased expenditure related to energy developments within a region: demand-driven IO and CGE. Both of these are useful frameworks as system-wide models allowing for

\footnotetext{
2 End of 2008 to End 2018

${ }^{3}$ The focus of this study is on fixed offshore wind farms only. Floating offshore wind is not accounted for,.
} 
the interdependencies between different parts (sector) of the economy to be captured, and show the sectoral disturbance of expenditure changes. This section sets out first, both modelling framework used in analysis, and second, how to estimate the spending associated with offshore wind developments in Scotland which is then introduced to these models to produce the results seen in Section 3.3.

\subsection{Input-Output (10) Model}

Fundamentally 10 models are based on a set of simultaneous equations which records the sectoral linkages of an economy in an 10 table, from the Leontief inverse can be produced matrix, $(\boldsymbol{I}-\boldsymbol{A})^{-\mathbf{1}}$ [21].

$$
\begin{gathered}
X_{1}=a_{11} X_{1}+a_{12} X_{1}+. .+a_{1 n} X_{1}+f_{1} \\
X_{2}=a_{21} X_{2}+a_{22} X_{2}+. .+a_{2 n} X_{2}+f_{2} \\
X_{n}=a_{n 1} X_{n}+a_{n 2} X_{n}+. .+a_{n n} X_{n}+f_{n}
\end{gathered}
$$

$X_{i}$ is the output of sector $i$ and $a_{i j}$ is a coefficient which represents the output of sector i needed to produce the one unit of $j$, calibrated using information from an $I O$ table. $f_{i}$ is the output of sector $i$ satisfying sales to final demand. In matrix notation this can be represented by:

$$
\boldsymbol{X}=\boldsymbol{A X}+\boldsymbol{F}
$$

and rearranged to:

$$
\begin{aligned}
X & =(I-\boldsymbol{A})^{-1} \boldsymbol{F} \\
\Delta \boldsymbol{X} & =(\boldsymbol{I}-\boldsymbol{A})^{-1} \Delta \boldsymbol{F}
\end{aligned}
$$

$\mathbf{I}$ is an identity matrix, with $(\boldsymbol{I}-\boldsymbol{A})^{\mathbf{- 1}}$ the Leontief inverse matrix representing the sectoral interdependencies within the economy. An exogenous change in final demand will, through the Leontief inverse matrix, stimulate changes in sectoral output across the whole economy. Demand driven 10 can be used to measure the effect of an increase in demand on different economic variables - in particular output, employment and GVA - through the use of multipliers. Through adding coefficients can measure the change in a range of variables, including employment ${ }^{4}$.

There are two variations of the demand-driven 10 model (Type I and Type II), which differ in their treatment of households' incomes and expenditure. For Type I specification the household sector is

\footnotetext{
${ }^{4} \Delta \boldsymbol{M}=\boldsymbol{m}_{\boldsymbol{i}}(\boldsymbol{I}-\boldsymbol{A})^{-\mathbf{1}} \Delta \boldsymbol{F}$, where elements within $\mathrm{M}$ reveal the impacts on employment at the sectoral level.
} 
treated as exogenous to the model and is not included in the $\mathbf{A}$ matrix. A Type I multiplier captures the "direct" (the initial change in demand) and "indirect" changes (those changes stimulated across the sectors in the economy) resulting from a unit change in final demand for the output of a sector.

Type II analysis incorporates an additional term: the "induced effect". An increase in the final demand requires some degree of increased labour input, reflected in increased payment to compensation of employees. This in turn will generate additional increases - due to households having an increased level of incomes to spend - in final demand and thus output. This effect is calculated by 'closing' the 10 modelling to endogenise household consumption; expanding the $\mathbf{A}$ matrix to add a row and column representing household labour inputs and consumption [21].

With demand-driven IO model there are two fundamental assumptions. The first is the assumption of fixed technical coefficients whereby (sectoral) output is always generated through the same pattern of sectoral inputs. 10 models do not allow for substitution between inputs to production e.g. if sector $i$ provides $50 \%$ of inputs into sector $j$, for any change in the size of sector $j$, this ratio will hold. Secondly, in demand-driven 10 models the supply side is assumed to be completely passive: changes in economic activity only attributed to the change in demand. This assumes that the increase in demand is always met without increasing pressure on prices, wages or labour supply. In a CGE model, which explicitly models the supply-side with the demand-side of the economy, these restrictions can be relaxes. Because of these constraints demand driven 10 models can be thought of as a special-case of CGE models [22].

Given the large expenditures necessary for offshore wind developments, it would be expected that there will be not only demand-side impacts but also supply-side impacts. The development of Scottish offshore wind capacity will increase the demand for labour, for instance. Both the IO model and CGE (with different closures) will give different levels of employment - which can be viewed as benchmarks. With no supply side constraints, 10 benchmarks the employment related to the increase in demand throughout the economy with no changes in prices. However, with through the use of CGE models supply-side constraints (such as wages and labour supply) are introduced which impact employment related to increases in demand. An increase in demand for product in the economy will drive up prices (including wages) which attracting migration increasing the labour supply, thus impacting employment (supply-side) impacts. Through the use of production functions other than Leontief, CGE allows for substitution between inputs which are determined by relative prices. 


\subsection{The AMOS CGE}

This AMOS framework has been used in a number of applications [23][24] and allows for a degree of flexibility in choice of model closures and parameters. The model can be run with either a myopic or forward-looking specification with the expectation of agents differing. This means that the produced results show the economic impact of the same set of demand disturbances under both model closures. In the myopic specification agents have adaptive expectations whereas in the forward looking specification, firms and consumers have perfect foresight.

Fundamentally, the model assumes that producers minimise cost using a nested multilevel production function. The combination of intermediate inputs with RUK and ROW inputs is based on the Armington function [25]. Output is produced from a combination of composite intermediates and value added, were labour and capital combine in a constant elasticity of substitution (CES) function to produce value added, allowing for substitution between these factors in response to relative price changes.

The production structure for all sectors, apart from electricity supply, is the same with this being illustrated in Appendix A. In this standard production function intermediate ${ }^{5}$ goods are a combination of non-energy and energy goods, with the energy composite separated in electricity and nonelectricity goods. In the next nest electricity is a combination of coal and non-coal, with non-coal being made up by oil and gas.

Electricity inputs are unique in this version of the model. All sectors, except electricity supply, purchase electricity from the electricity supply sector, thus the production structure in Appendix B. This electricity supply sector however purchases from generation technologies directly meaning a more complex production structure.

Most of the electricity supply production structure is similar to that for the other 16 sectors in the model, the difference being that the energy composite - specifically with electricity - has been separated further.. Electricity is a combination of intermediate and non-intermediate generation functions with each being made up of different technologies. The intermediate function has both onshore and offshore wind along with marine renewables while non-intermediate has seven technologies: coal, gas, pumped hydro, nuclear, marine and biomass - separated into low carbon and coal generation. Using this two production structure, the electricity supply sector acts as an

\footnotetext{
${ }^{5}$ Energy has been incorporated into the model as part of intermediated goods [26].
} 
intermediate between the electricity generators and other sectors. This is similar to the electricity market where consumers purchase electricity from suppliers rather than directly from generators.

There are four components of final demand in the model: household consumption, investment, government expenditure and exports. Household consumption is a linear function of real disposable income. Government expenditure in the model is constant in the model, while exports are determined by an Armington function [24] thus are dependent on relative prices.

All simulations are run in a multi-period setting, with the periods interpreted as years as both the SAM and behavioural relationships are benchmarked using annual data. The model is initially assumed to be in steady-state equilibrium, implying that with no exogenous disturbances, the model simply replicates the initial value over all subsequent time periods.

The supply-side of the economy determines the use of capital and labour in the model. Capital is fixed in the first period but in subsequent periods each sectors sector's capital stock is updated through investment. In the myopic specification investment is set as a fraction of the gap between the desired and actual (adjusted for depreciation) level of capital stock - in line with the neoclassical investment formulation [27]. For investment decisions within the forward-looking model the rate of investment is a function of the ratio of the value of firms to the replacement cost of capital [28]. In the framework the path of investment is modelled as:

$$
\operatorname{Max} \sum_{t=0}^{\alpha} \frac{1}{(1+r)^{t}}\left[\pi_{t}-I_{t}\left(1+g\left(x_{t}\right)\right)\right]
$$

Here a firm is maximising cash flow from a given profit $\pi$, private investment $I_{t}$ and adjustment cost $g\left(x_{t}\right)$.

Consumers, under the forward-looking expectation, maximise the present value of a utility using the following life-time utility function [23].

$$
U=\sum_{t=0}^{\alpha}\left(\frac{1}{1+\rho}\right)^{t} \frac{C_{t}^{1-\sigma}-1}{1-\sigma}
$$

The consumption at time $\mathrm{t}$ is $\mathrm{C}_{\mathrm{t}}$ with $\sigma$ the elasticity of marginal unity and $\rho$ the constant rate of time preference. Budget constraints ensure that the present value of consumption does not excess household wealth. In the myopic expectation, with no perfect foresight, consumption is a linear function of disposable income.

Labour force changes in the model (both myopic and forward-looking specification) are completely attributed to migration as there is no change in natural populations. Migration to Scotland is 
determined by the gap between the Scottish and UK unemployment rates as well wages and consumer price index. The regional economy is assumed to have zero net migration in the base year (2012).

A single labour market with perfect sector mobility is imposed on the model and it is assumed that wages are subjected to a bargaining function whereby the wage is directly related to workers bargaining power, which is taken to be inversely related to the unemployment rate.

\subsection{Scottish offshore expenditures.}

There are three main stages of expenditure in the development of offshore wind capacity - DEVEX (development) CAPEX (construction) and OPEX (operation). Estimates are needed of each for each Scottish offshore wind development. The modelling specially requires information on three pieces of information: the scale of spending associated with the wind farms under consideration; the timing of expenditures associated with these projects; and the category of spending and the portion of each category of expenditure made in Scotland.

Renewables UK publish annual reports detailing the timeline and capacity of offshore wind farms in Scotland, combining this information with the valuation of cost per MW, the total expenditure per wind farm is calculated. Due to the complexity of development the cost of $\mathrm{MW}$ can vary greatly offshore, for Scotland an estimate $£ 4$ million per $\mathrm{MW}$ is used - in line with previous studies but higher than the UK as a whole ${ }^{6}$ [29]. The environmental conditions experienced by Scottish offshore wind development are harsher than the UK as whole, requiring more infrastructure which acts to increase both capital and operation costs. However these location also contain higher wind resource meaning that, even with higher costs, the levelised cost of Scottish offshore wind remains competitive with the rest of the UK [30].

Capital expenditures on offshore wind devices fall within a number of different categories. The breakdown of these cost varies depending on a number of factors with location being key. For the cost breakdown of Scottish offshore windfarms information available from [31] [32] is used which estimates turbine costs to be around $39 \%$ which is in line with the other studies throughout literature [33]. Figure 1 outlines this cost breakdown.

\footnotetext{
${ }^{6}$ The higher estimate accounts for the harsher environments of development in Scotland
} 


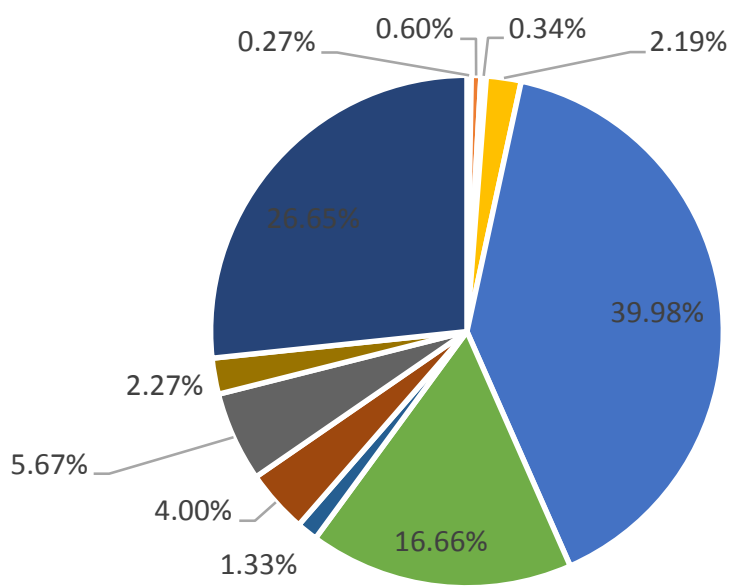

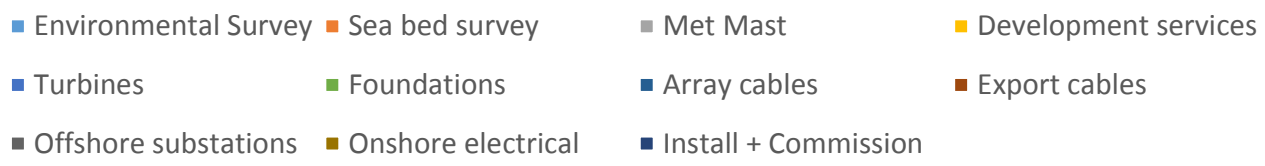

Figure 1. DEVEX AND CAPEX breakdown per MW

Along with the cost breakdown there is also need for a timing breakdown as capital costs are typically distributed over a number of years. Through investigating several Environmental Impact Assessments (EIA) its estimated that full development of a 'generic' UK offshore farm, from pre-development to full installation - takes six years with a yearly capital cost breakdown summarised in Table 2 .

\begin{tabular}{cccccc} 
Year 1 & Year 2 & Year 3 & Year 4 & Year 5 & Year 6 \\
\hline $0.37 \%$ & $1.82 \%$ & $16.43 \%$ & $32.12 \%$ & $27.13 \%$ & $22.11 \%$
\end{tabular}

Table 2. Yearly breakdown of CAPEX costs.

Operations and maintenance (O\&M) costs ARE made during the lifetime operation of the windfarm to ensure optimum output. In each of the simulations the assumption is made that each MW of capacity will be operational for 25 years at a cost of $£ 66,229$ per MW per year [34].

Key in determining the regional impacts of Scottish offshore wind developments is the proportion of expenditure kept within Scotland, i.e. local content. Establishing local content can be difficult; at the time of writing, there is only publically available information on the local content of one operational Scottish offshore (Robin Rigg, built in 2012) [35]. This farm is nearshore, and so the pattern may be quite different for future (further from shore) farms. Through consultation with developers, the local 
content for a 'generic' Scottish offshore wind farm is determined to be $17.06 \%^{7}$ and an operational local content of $38 \%{ }^{8}$.

Each stage of offshore wind development expenditures takes place in a number of sectors. As such a conversion is carried out using the offshore wind bridge matrix linking categories expenditures to industrial sectors. This bridge matrix converts the spending at each stage of development to SIC codes found within 10 tables and is found in the Appendix $C$. In the matrix each stage is related to various Standard Industrial Classification SIC codes based on expenditure shares. Figure 2 shows the expenditures introduced into the model by period separated into five broad industrial sectors: manufacturing, electricity, construction, services and transport.

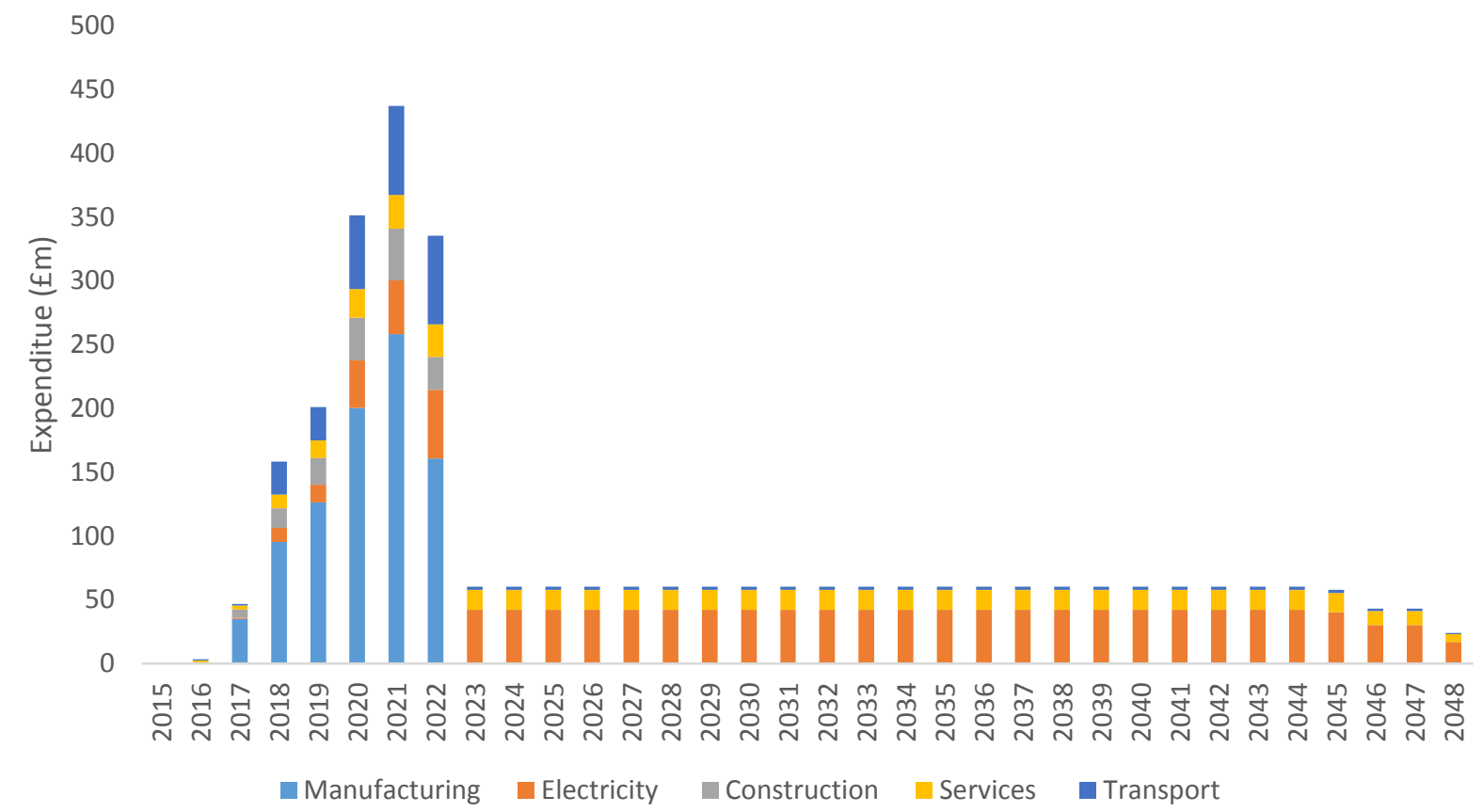

Figure 2. Expenditures introduced into model, $f$ million per year

These are the expenditures of all goods and services purchased within Scotland for all modelled wind farms. Peak expenditure occurs at in 2021, relating to the construction of the two largest wind farms - Moray East and Neart Na Gaoithe. By 2023 all wind capacity has been installed and the expenditures reduce significantly with most of relating to the electricity (mostly offshore wind) and service sectors.

\footnotetext{
${ }^{7}$ As this is 'averaged' numbers the local content for individual farm may be different. Indeed increased increasing local content is of specific interest in recent energy policy such as the offshore wind sector deal [36] 8 [37] investigates the importance of local content assumptions
} 


\subsection{Database and simulation strategy.}

Fundamentally, the simulations using $I O$ and CGE models use much of the same information ${ }^{9}$. The Scottish Government regularly publish annual IO tables, with the 2012 table being used for the analysis of Scottish offshore wind. As displayed in the offshore wind bridge matrix, some of the expenditure is related directly to the offshore wind sector, thus it is advantageous to use an electricity disaggregated IO and CGE model, otherwise this would be included in the aggregated electricity sector.

As a comparison against the 10 method, this paper uses a version of the CGE modelling framework AMOS [23] calibrated on a 17 sector Social Accounting Matrix for Scotland containing 13 energy focused sectors. In addition to the 17 sectors/commodities, within the model there are three internal institutions - households, firms and governments - and two external transactors, the rest of the UK (RUK) and the rest of the world (ROW). Scotland is considered to be a small open economy and it is assumed that it has no impact on international and inter-regional markets such that RUK and ROW prices are exogenous. Commodity markets are assumed to be competitive. Financial flows are not explicitly modelled, and the interest rate is assumed to be exogenous. Figure 3 outlines the simulation strategy of the CGE model.

\footnotetext{
${ }^{9}$ The SAM for the CGE is an extension on an IO table which records the linkages between institutions (households, governments, corporations) and the rest of the economy.
} 


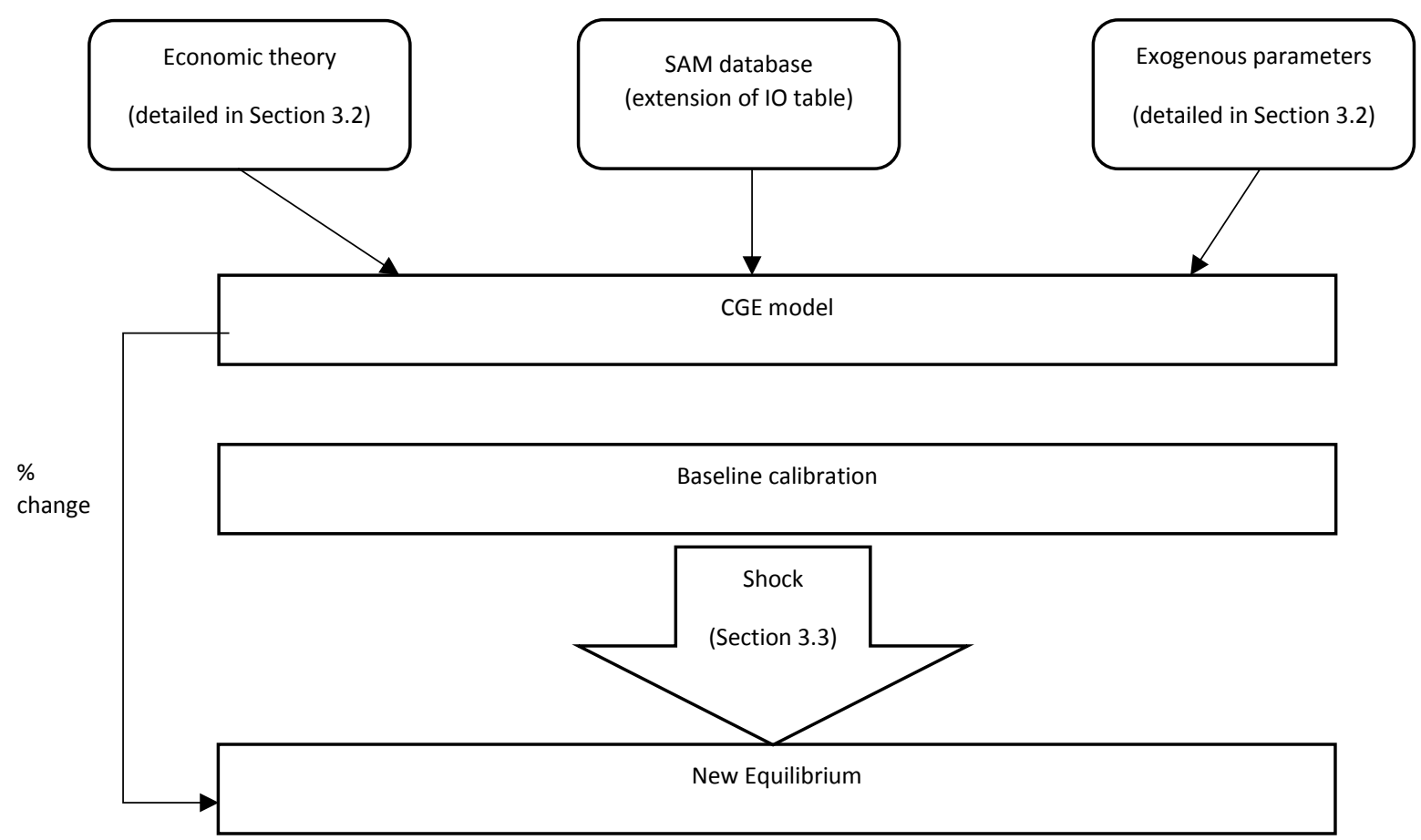

Figure 3: Computational process of CGE modelling.

Before any simulations are run a calibration is carried out by running the model without the introduction of any policy or exogenous demand shocks. This allows the model to reproduce the original data set (SAM) while setting up a reference equilibrium and key to the modelling, calibrate the parameters.

In both, the IO and CGE model, the offshore wind developments expenditures - given in Figure 2 - are introduced into the model as a series of exogenous demand shocks to individual sectors in each of these years. 10 impacts are estimated using the method outlined in Section 3.1. In the CGE model the shock induce price variations, affecting the consumption and productions and services until a new equilibrium point is reached. For both $I O$ and GGE the model is run forward for a total of 50 periods (years) so the timing of economic impacts attributable to these expenditures can be understood. 


\section{Results and discussion}

\subsection{Cumulative impacts}

The results can be separated into three distinct time periods: those during project development and construction (2015-2022); during operational and maintenance (2023-2048) and legacy in the period from 2048 onward, after expenditures cease. These can further separate the 10 modelling results into direct, indirect and induced. Below shows the cumulative (non-discounted) results on employment in Figure 4.

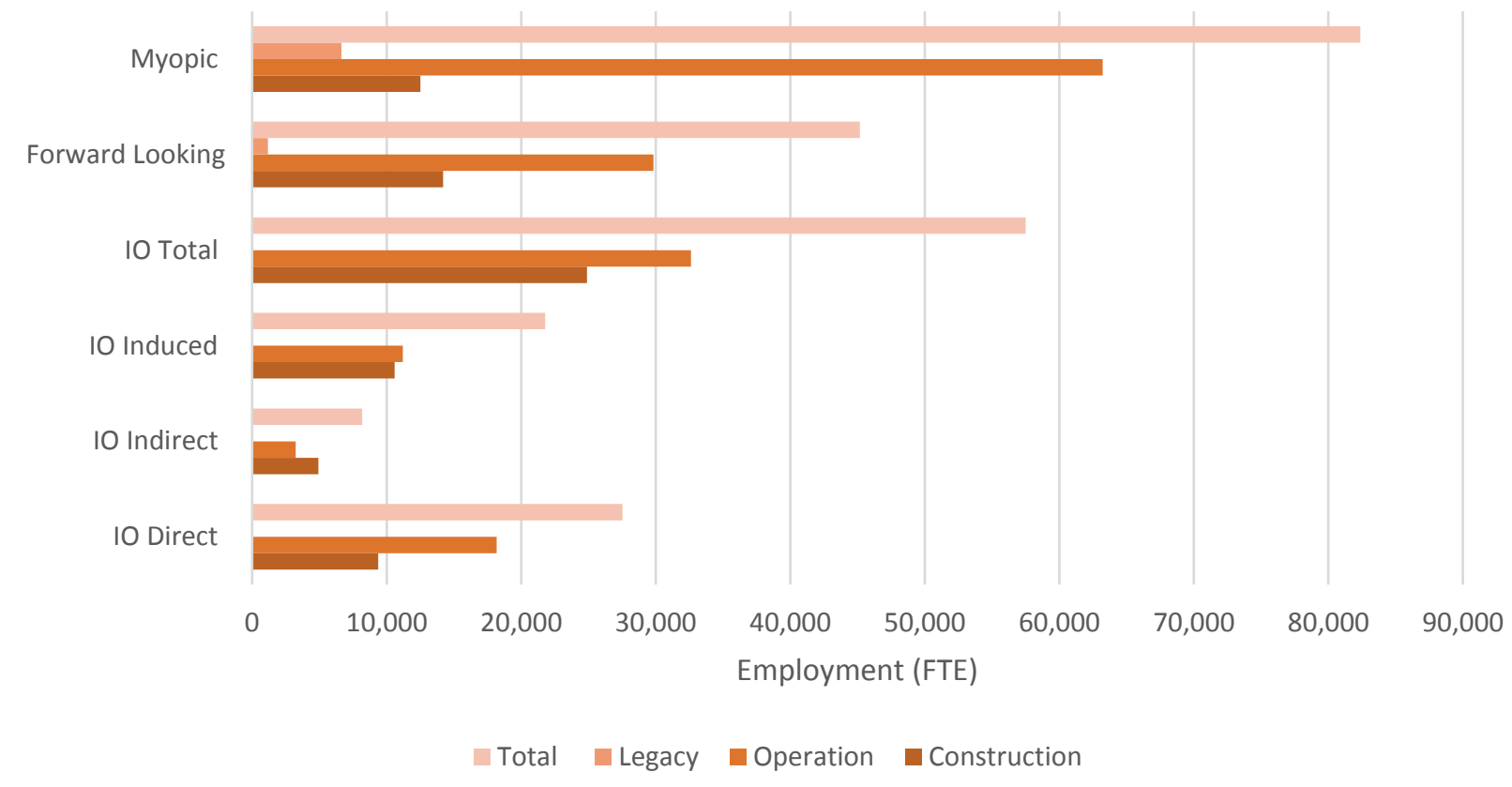

Figure 4. Absolute cumulative impacts for Employment, FTE

The introduction of expenditures leads to an increase in employment in Scotland in all three simulations. Total IO employment impacts are much larger that the CGE simulations at the construction stage - as the 10 model is not limited by the supply side and solely demand driven, and the expenditures are largest at this stage. Comparing the 10 results, the direct impacts account for $47.9 \%$ of totally impacts with indirect $14.2 \%$ and induced $37.9 \%$. The construction stage represents $60.30 \%$ of total indirect 10 impacts indicating that the Scottish offshore wind supply chain in much more active in the construction stage than the operational stage.

The myopic simulation has the largest overall employment with 82,393 compared with the total IO impact of 57,498 FTEs and forward-looking 45,181. Most of the myopic employment impacts (78.6\%) 
is attributed to the period in which the offshore wind developments are operational. Myopic simulations are reactive thus during the construction stage there is a build of labour supply and capital stock which reduces over an extended period of time. In the 10 model the impacts are determined by the expenditures, which are much lower during the operational stage hence the lower yearly impacts ${ }^{10}$. In the CGE model with forward-looking behaviours capital stock and labour supply do not increase as much as myopic with their reduction occurring quicker during the operational stage.

Each of these modelling frameworks are used for different purposes and it advantageous to compare the results. The purpose of this paper is not to give an exact number of the economic impact of Scottish offshore wind, but rather the potential scale of impacts, with the models/closures acting as benchmarks. With an 10 model impacts are solely related to the expenditure and as such during the construction stage this modelling gives the largest scale impacts. However due to the scale of investment the development of Scottish offshore wind is likely to impacts on prices, wages and labour supply which is captured through the use of CGE models. Under the both closures - myopic and forward-looking - it's found that during the construction stage impacts are lower due with supply side constraints. However, under the myopic closure there is a large build-up of capital stock and labour leading to larger impacts, during the operational stage, than the 10 model.

In previous studies of Scottish offshore renewables [24] this is not the cause as only capital expenditure is modelled. The economic impacts of an 10 model are solely related to the size of the shock thus in our simulation in the transition to the operational stage there is a large instant reduction in 10 economic impacts. However, with the myopic model with the supply side constraints the reduction of impacts in slower than IO. With forward-looking closure the build-up of capital stock and labour is not as large, thus the economic impacts are lower that both myopic and IO. Overall the myopic simulations yield the largest impacts followed by 10 and forward-looking.

The next sections described, in detail, the economic impacts of Scottish offshore wind developments using the three outlined models and closures. Figures 5 and 6 are the GVA and employment impacts using the three methodologies. As 10 models do not include supply-side changes Figures 6-10 only detail the impacts of the myopic and forward-looking closures on: wages; labour supply; household consumption; capital stock and CPI.

\footnotetext{
${ }^{10}$ There is larger overall impacts during operation as the time period ( 25 years) is much greater that the construction period of 9 years.
} 
As previously identified IO modelling is a special form of a CGE with several underlining assumptions - most notably the passive supply side and fixed technical coefficients. With this passive supply side the economic impacts within 10 modelling are directly related to the demand shock.

From Figure 6 in 2015 and 2016 the employment impacts are very small in the IO simulation, mirroring the demand expenditures from Figure 2. As the expenditures begin to increase, so do the GVA and employment impacts (Figures 5 and 6 ). Both the peak GVA of $f 410$ million and employment $(7,102$ FTEs) are reached in 2021 - the peak expenditure year. Once all turbines are constructed there is a large reduction in 10 impacts due to the expenditure from 2023 only comprising of operational and maintenance elements. Finally, once the lifetime of the last turbines is reached (2049) there are no more IO GVA or employment impacts. In Figures 6-10 there are no 10 impacts as this modelling does not impact prices or the supply-side of the economy

\subsection{CGE with Myopic behaviours}

With myopic specification the agents react to the demand shocks and prices and have no future foresight.

Figure 5 illustrates Gross Value Added (GVA) impacts under the myopic closure are much less than IO between 2015 and 2022. The peak of GVA, in the myopic specification, is only $£ 178.52$ million compared with the $10 £ 410.67$ million, with the reduction primarily caused by crowding-out effects. With an active supply side in the CGE model both the prices and wages have increased which reduces the competitiveness of sectors - particularly affect those with high level of exports.

Unlike in the IO simulation where there is a large drop off in the GVA impacts once the O\&M stage starts (2023), the myopic GVA does not peak until 2023. This occurs as in the myopic simulation there has been a large build of capital stock during construction (Figure 10).

In Figure 6 the scale of employment during the CAPEX stage is much greater for the IO simulation than the myopic, the peak myopic employment for the myopic is 4,323 FTEs reached 2022, 1 period after the peak demand shock. In contrast with construction stage, during O\&M the employment is actually larger under the myopic specification than IO. Thus occurs as the myopic (unlike IO) impacts are a results of both supply side effects and the demand disturbance.

During the construction stage of the project both the real and nominal wages are found to increase, as would be expected. At this time there is a squeeze on employment and thus the employees are 
able to bargain for higher wages. Once construction is finished though (2023) there is a sharp fall in the wage rates, indeed they become lower than in the initial period. With the increase in labour supply there is more employees than required and the wage rate drops as employees cannot bargain for higher wages at this stage.

Through design, migration is allowed within the model and the labour force will flow to (from) Scotland if the real wage rate is higher (lower) than the national, i.e. UK, rate. From Figure 8 the labour supply sees a large increase during the construction stage reacting to the large increase in real wages (Figure 7). Labour supply peaks in 2023, one period after the construction stage. The peak does not occur during the construction stage as there are still significant demand shocks and the average wage larger than the references year thus the migration is still reacting to this, not expected the reduction in expenditure after the construction stage. After 2022 there is a significant reduction in the labour supply as out-migration occurs due to the fall in wages to below the baseline values. Once the demand disturbances reduce to zero, the labour supply reaches equilibrium again at period 50 (which is the imposed equilibrium point from the modelling).

In the myopic case the level of consumption (Figure 9) is related to household spending power. During the construction stage of the project, there is a large increase in the household consumption, occurring due to the wage increase found in Figure 9. At the O\&M stage of the project when the wage rate drops there is as a decrease in household consumption, however due to the lower CPI at this stage (Figure 11) this reduction is steady.

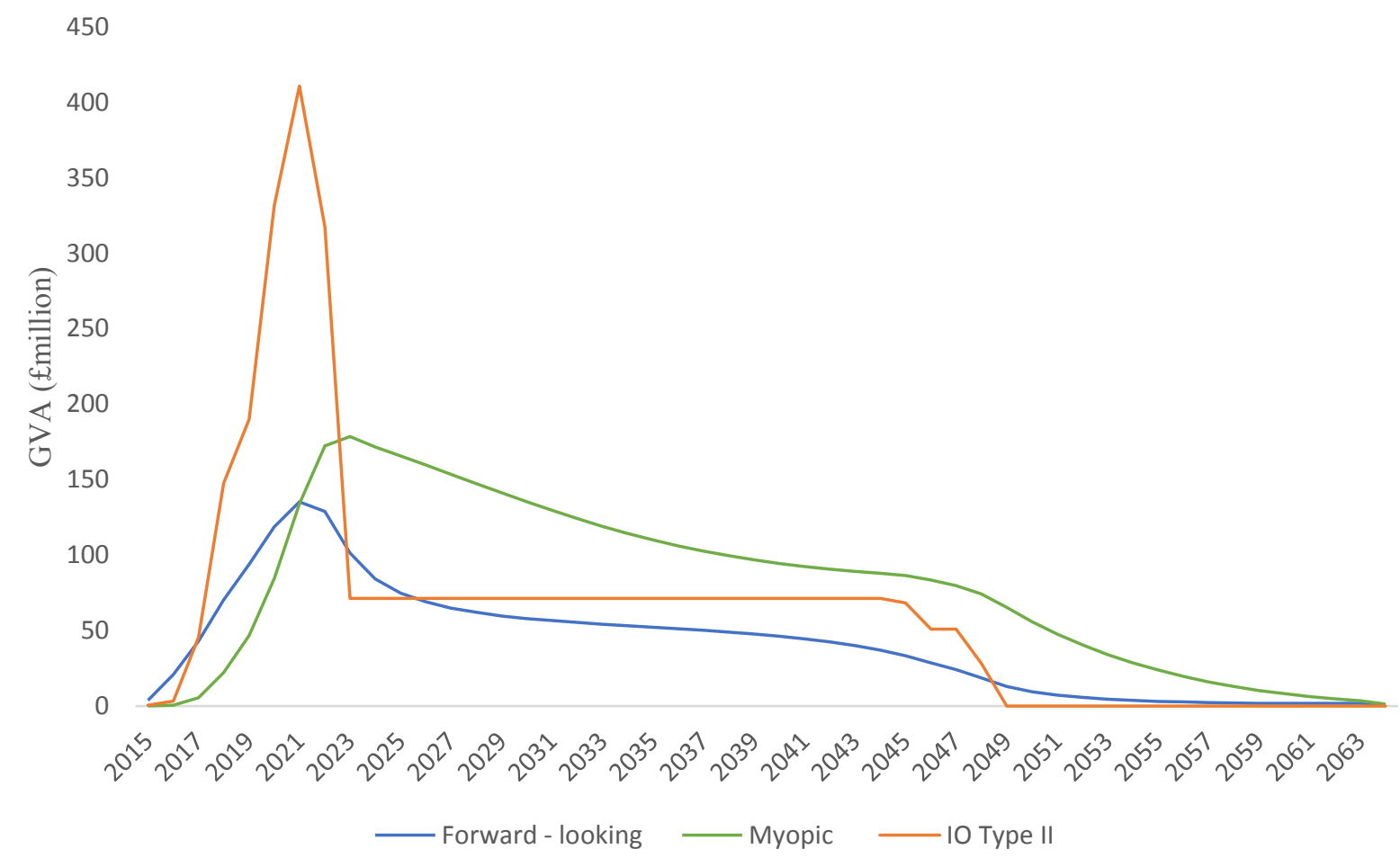


Figure 5. GVA impacts for planned Scottish offshore wind developments to 2022

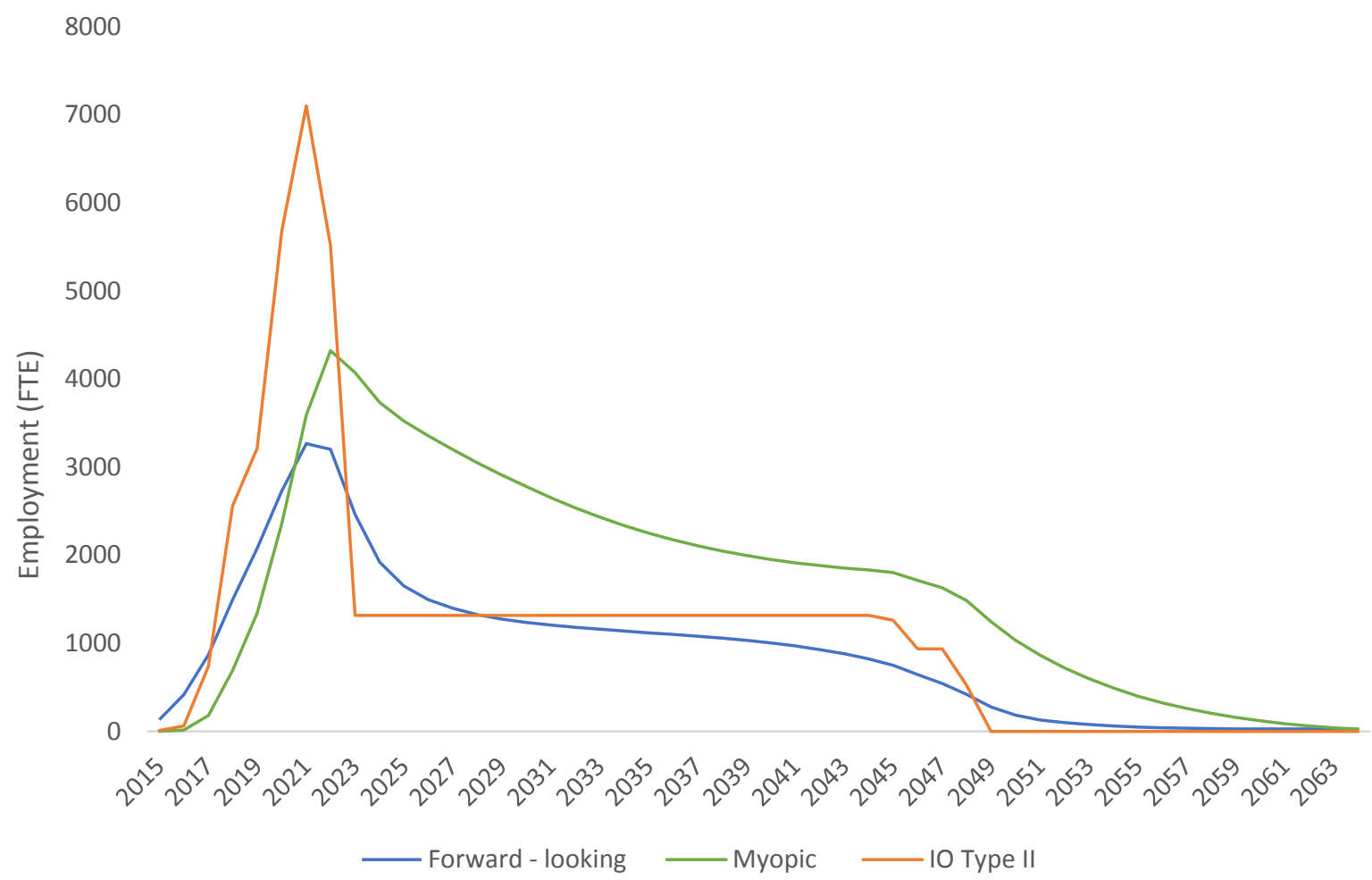

Figure 6. Employment impacts for planned Scottish offshore wind developments to 2022

0.25

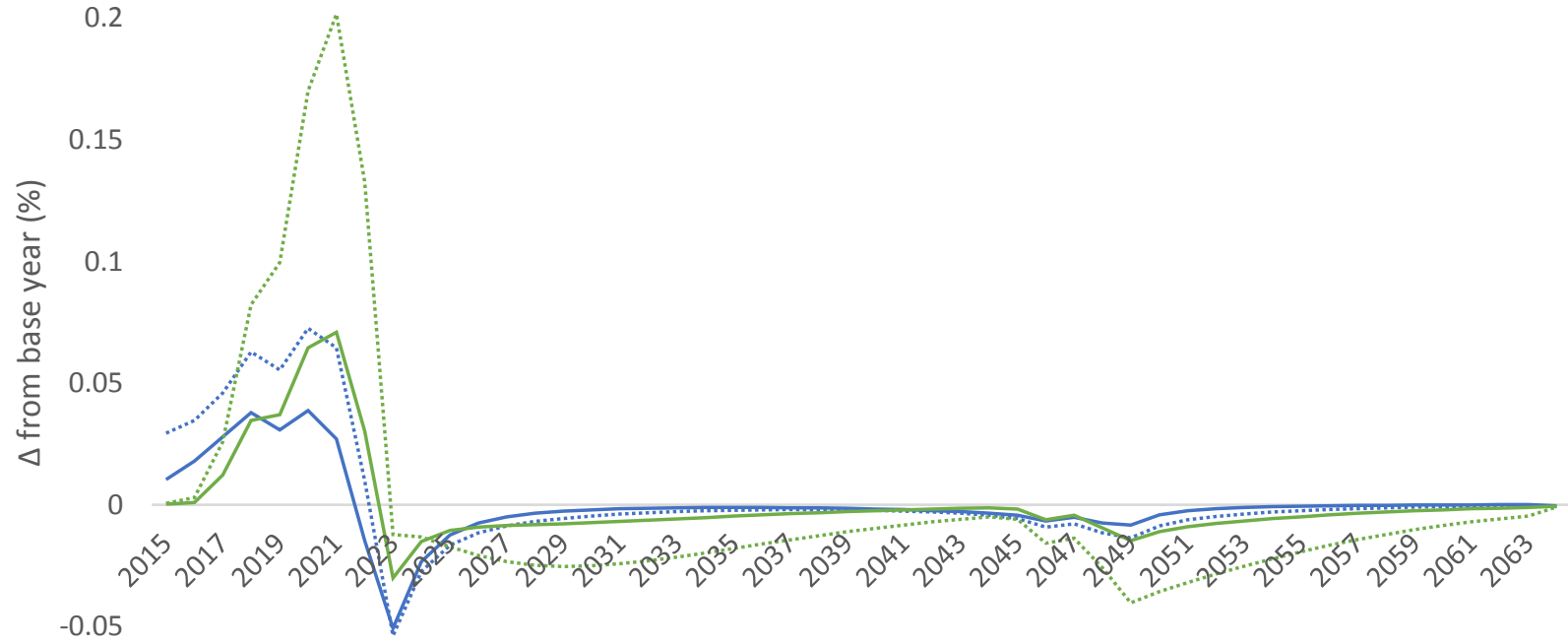

$-0.1$

Figure 7. Wage rate impacts for planned Scottish offshore wind developments to 2020 
0.2

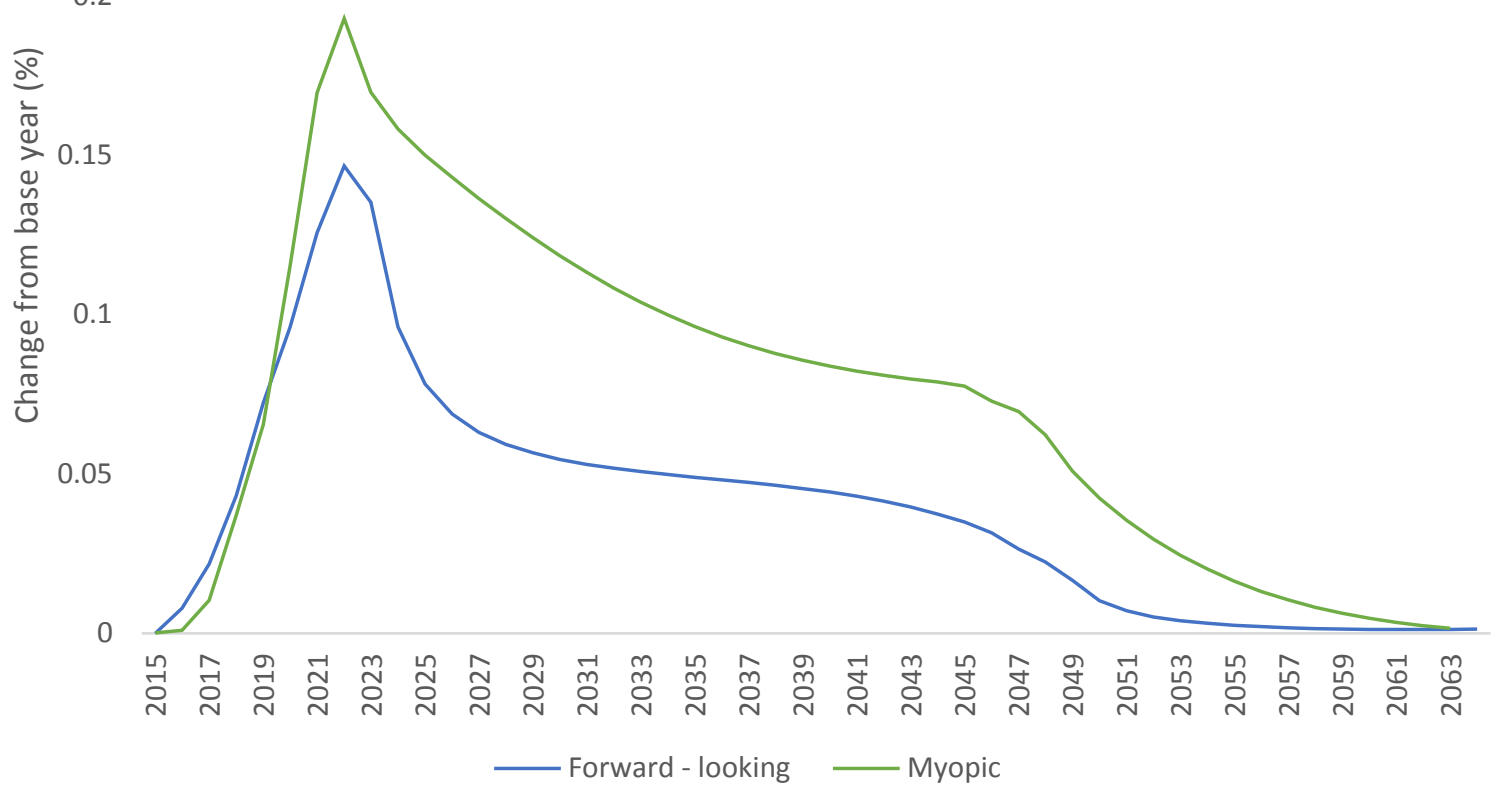

Figure 8. Labour supply variations impacts for planned Scottish offshore wind developments to 2022

0.2

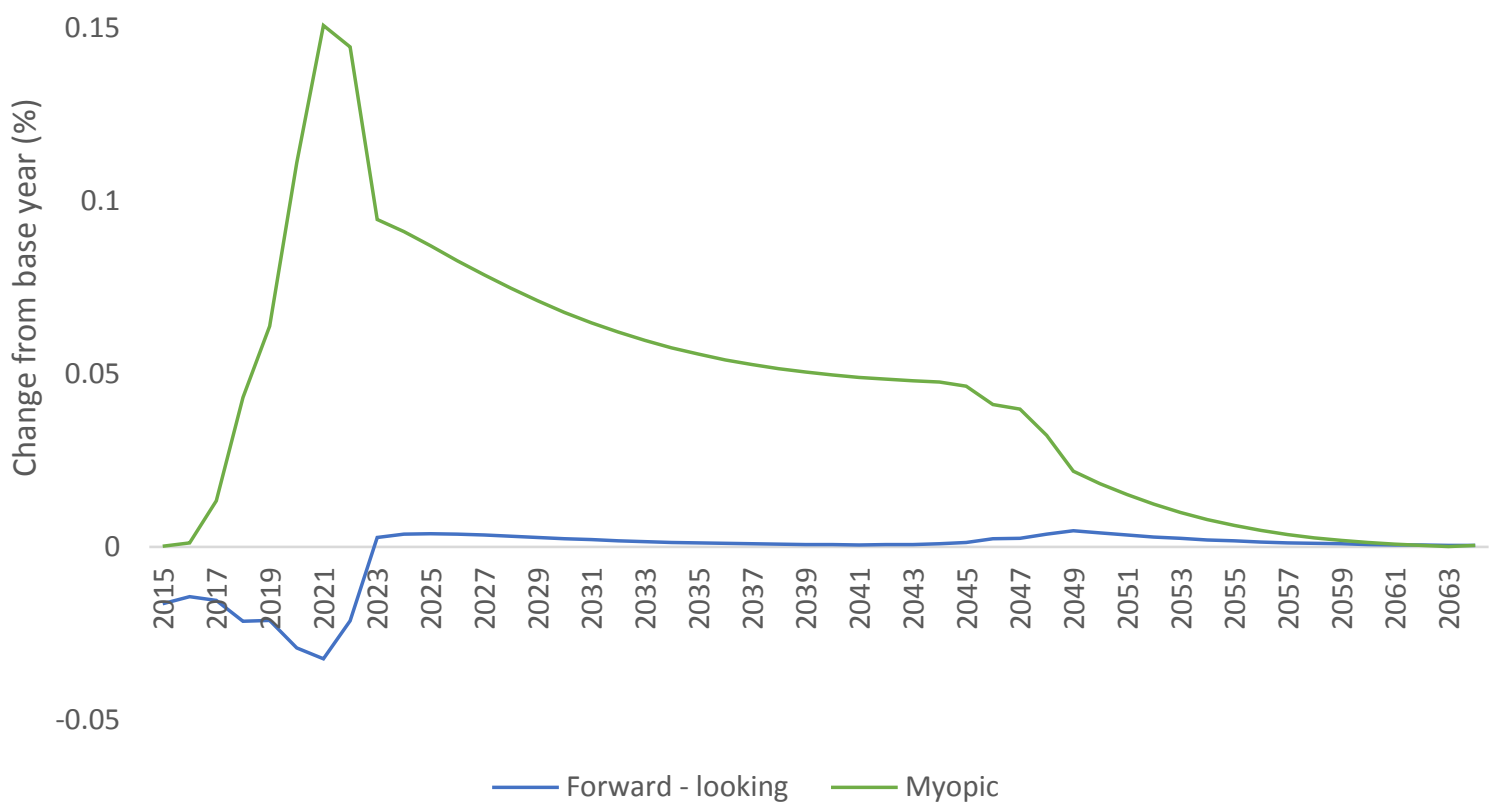

Figure 9. Household consumption impacts for planned Scottish offshore wind developments to 2022 


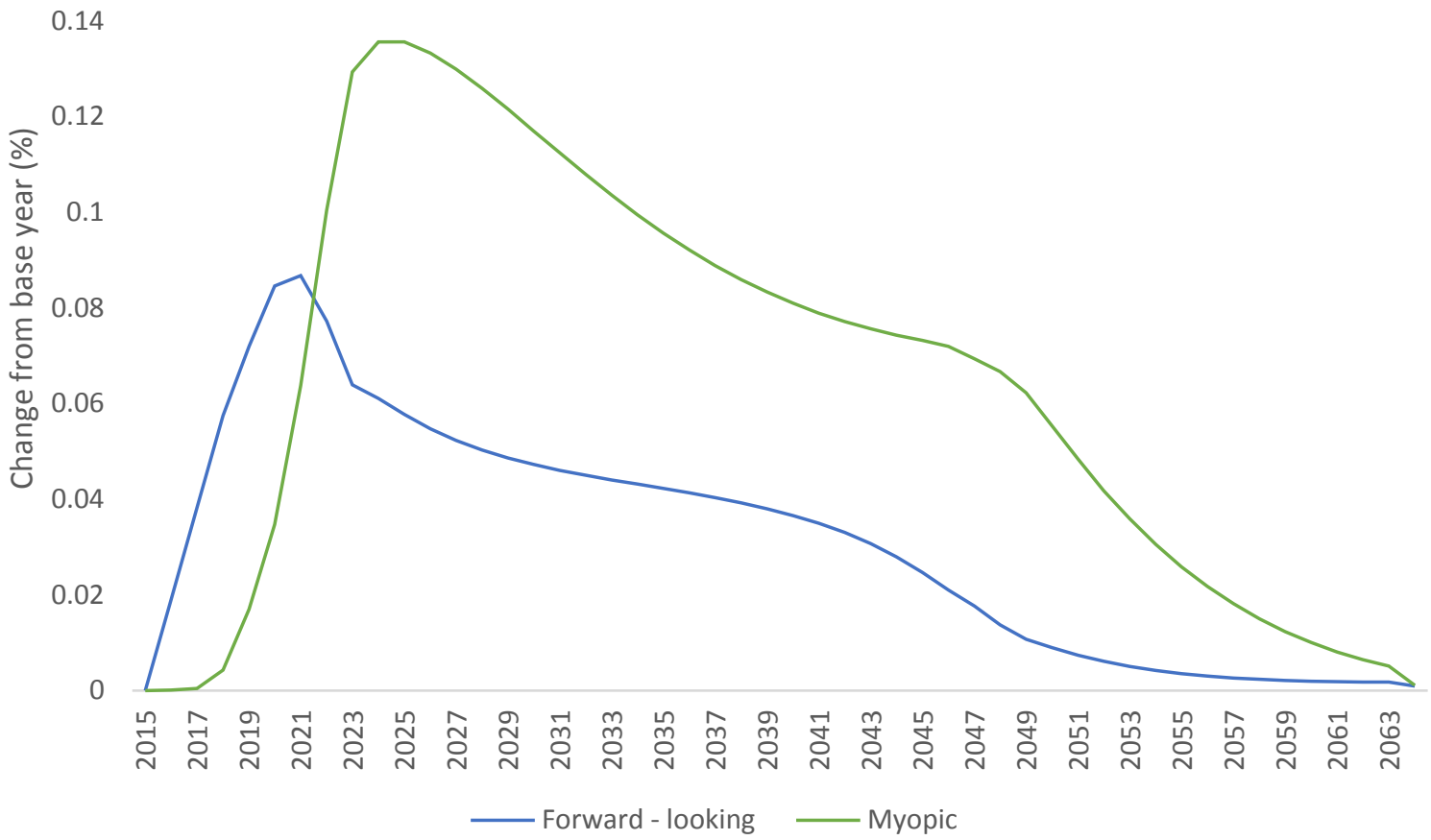

Figure 10. Capital stock impacts for planned Scottish offshore wind developments to 2022

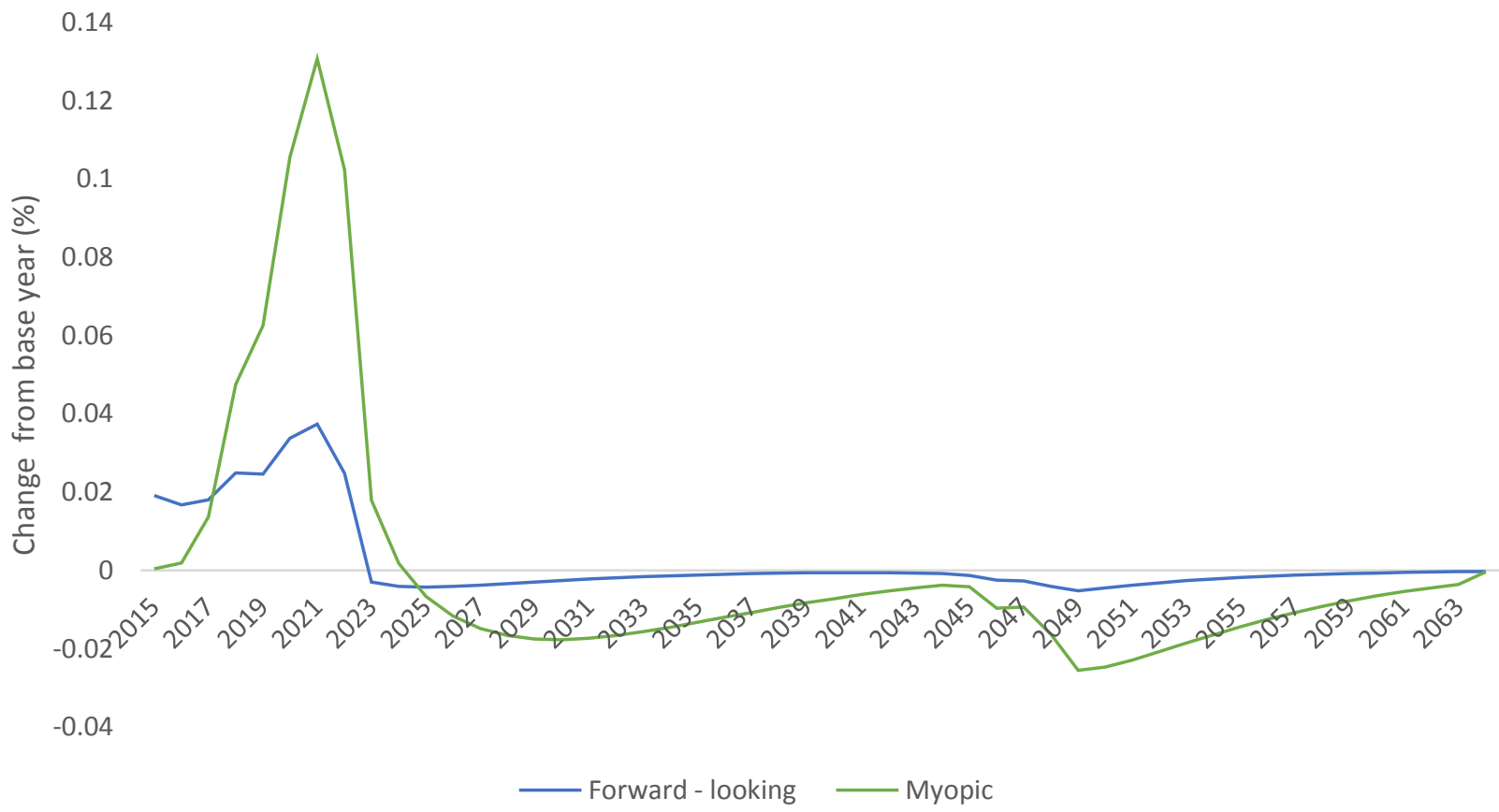

Figure 11. CPI variations impacts for planned Scottish offshore wind developments to 2022 


\subsection{Forward-looking}

The difference between the myopic and forward looking closure is than rather than being reactive, future prices impact on firms' investment and households' consumption decisions.

The peak (positive) change in forward-looking GVA (2021) occurs much closer to the peak in expenditures in the myopic case. With the increase in demand and prices anticipated at earlier periods, earlier investment is made in capital stock in the forward-looking simulation, effecting GVA. Also, the increase in capital stock is lower in the forward-looking case, adding to smaller GVA legacy effects.

Forward-looking employment impacts (Figure 6) follow a similar pattern to the GVA in that the impacts are lower than myopic at all periods. During the construction stage there are two main drivers behind this smaller impact. Firstly, the changes in prices are known thus there is an expectance of only a temporary demand. Secondly, from Figure 11, during the periods of peak demand disturbances (20192021) the forward-looking capital stock (which can be substituted for labour) is larger than myopic.

In the forward-looking case the pattern for wage rates is similar with the scale being different (Figure 7). During the construction stage there is less wage bargaining with the expected drop in prices. Whereas after the construction stage the forward-looking wages drop further than the myopic. Figure 8 shows also that the migration effects are lower in the forward-looking case due to the lower wages,

Differences in time-path of some variables with forward-looking and myopic closures of the CGE model, there are some with major difference.

Under the forward-looking specification, households' foresee the large increase in Consumer Price Index (CPI) (Figure 11) during construction stage thus reduce their consumption in those periods. CPI then reduces below the initial value after the project has ended and at this time find an increase in the household consumption with the lower prices - maximising utility.

\section{Conclusion}

The key objective of recent Scottish energy policy has been to significantly reduce greenhouse gas emissions, an objective in which the decarbonisation of electricity generation will play a pivotal part. With $25 \%$ of the total European resource, Scottish offshore wind capacity is expected to increase dramatically over the coming years. This will not only reduce greenhouse gas emissions, but is anticipated to also have economic benefits as a result of large investment in project construction and operation. The modelling helps Scottish policy makers to understand the possible qualitative size of 
the economic "prize", its timing, and how these estimates differ with the use of different modelling frameworks.

This paper has used regional multi-sectoral system-wide models (IO and CGE) to estimate and compare the economic impacts resulting from the planned increase in offshore wind capacity to 2022 IO models are widely used in economic impact analysis but do have some limitations such as the passive supply side thus enhances the analysis through the use of CGE models. The CGE model used has two alternative agent behaviours - myopic and forward-looking - each of which produce different scales of economic impacts.

The paper finds that the planned offshore wind developments in Scotland will bring considerable economic benefits to Scotland with an increase in output, GVA and employment.

The myopic simulation yields the largest overall results with a total GVA impact of $£ 3.88$ billion and increase in employment of 82,393 person years of employment. With the forward looking simulation the GVA impact is $£ 2.04$ billion and employment 45,181 while for the IO Type II the increases are $£ 3.22$ billion and 57,498 FTES. This result differs from [25] where 10 impacts of Scottish offshore renewable are the largest. These results focus on both the construction and operational stage, with the myopic results being largest due to the build-up of capital stock during wind farm construction.

This research can be extended in a number of ways. First, this paper only focused on the economic impacts of increasing Scottish offshore wind capacity, one of the pillars of the energy quadrilemma. An extension of this work would be to investigate the impact the increase in offshore wind capacity will have on the other pillars of the quadrilemma: emissions, energy security and energy prices. An increase in offshore wind will likely decrease emissions by replacing fossil fuel generation however, with the technology being intermittent there is potentially negative impacts on energy security. Also with the use of a CGE model, a further extension would investigate the impact learning has on the labour and capital productivity of offshore wind and how this impacts the economy. 


\section{References}

[1] Wind Europe. (2018). Offshore wind in Europe Key Trends and statistics. Retrieved from https://windeurope.org/wp-content/uploads/files/about-wind/statistics/WindEurope-AnnualOffshore-Statistics-2018.pdf

[2] Olabi, A. G. (2016). Energy quadrilemma and the future of renewable energy. Applied Energy, 108, 1-6. https://doi.org/10.1016/j.energy.2016.07.145

[3] Markaki, M., Belegri-Roboli, A., Michaelides, P., Mirasgedis, S., \& Lalas, D. P. (2013). The impact of clean energy investments on the Greek economy: An input-output analysis (2010-2020). Energy Policy, 57, 263-275. https://doi.org/10.1016/j.enpol.2013.01.047

[4] Fanning, T., Jones, C., \& Munday, M. (2014). The regional employment returns from wave and tidal energy : A Welsh analysis. Energy, 76, 958-966. https://doi.org/10.1016/j.energy.2014.09.012

[5] Jenniches, S.. (2018). Assessing the regional economic impacts of renewable energy sources A literature review. Renewable and Sustainable Energy Reviews, 93, 35-51.

https://doi.org/10.1016/j.rser.2018.05.008

[6] Scottish Government. (2011). 2020 Roadmap for renewable energy in Scotland. Retrieved from http://www.scotland.gov.uk/resource/doc/917/0118802.pdf

[7] Scottish Government. (2011). 2020 Roadmap for renewable energy in Scotland. Retrieved from http://www.scotland.gov.uk/resource/doc/917/0118802.pdf

[8] Allan, G. J., Lecca, P., McGregor, P. G., \& Swales, J. K. (2014). The economic impacts of marine energy developments: A case study from Scotland. Marine Policy, 43, 122-131.

https://doi.org/10.1016/j.marpol.2013.05.003

[9] Gilmartin, M., \& Allan, G. (2014). Regional Employment Impacts of Marine Energy in the Scottish Economy: A General Equilibrium Approach. Regional Studies, (November), 1-19.

https://doi.org/10.1080/00343404.2014.933797

[10] Okkonen, L., \& Lehtonen, M. (2017). Socio-economic impacts of community wind power projects in Northern Scotland. Renewable Energy, 85(January 2016), 826-833.

https://doi.org/10.1016/j.renene.2015.07.047

[11] Tegen, S., Keyser, D., Miles, J., Zammit, D., Loomis, D., (2015). Offshore Wind Jobs and Economic Development Impacts in the United States : Four Regional Scenarios Offshore Wind Jobs and Economic Development Impacts in the United States : Four Regional Scenarios. NERL report. Retrieved from http://www.nrel.gov/docs/fy15osti/61315.pdf

[12] Graziano, M., Lecca, P., \& Musso, M. (2017). Historic paths and future expectations: The macroeconomic impacts of the offshore wind technologies in the UK. Energy Policy, 108(November 2016), 715-730. https://doi.org/10.1016/i.enpol.2017.06.042 
[13] Royles, E., \& McEwen, N. (2015). Empowered for action? Capacities and constraints in sub-state government climate action in Scotland and Wales. Environmental Politics, 24(6), 1034-1054.

https://doi.org/10.1080/09644016.2015.1053726

[14] Scottish Government. (2019). Climate Change action. Retrieved from https://www.gov.scot/news/climate-change-action-1/

[15] Scottish Government. (2019). Energy Statistics database. Retrieved from https://www2.gov.scot/Topics/Statistics/Browse/Business/Energy

[16] Scottish Government. (2017). The future of Energy in Scotland: Scottish Energy Strategy. Retrieved from https://www.gov.scot/publications/scottish-energy-strategy-future-energyscotland-9781788515276/pages/3/

[17] UK Government. (2017). Contracts for Difference Second Allocation Round Results. Retrieved from

https://www.gov.uk/government/uploads/system/uploads/attachment data/file/643560/CFD alloc ation round 2 outcome FINAL.pdf

[18] Snodin, H., Gow, G., \& Garrad, A. (2001). Scotland's renewable resource. Analysis (Vol. I). Retrieved from

http://archive.scottish.parliament.uk/business/committees/enterprise/inquiries/rei/ec04-reisscotenvlinkfollowup2.pdf

[19] BEIS. (2019). DUKES chapter 6: Renewable electricity capacity and generation. Retrieved from https://www.gov.uk/government/statistics/energy-trends-section-6-renewables

[20] Renewable UK. (2018). Offshore Wind Projects Offshore Wind Project Timelines. Retrieved from https://cdn.ymaws.com/www.renewableuk.com/resource/resmgr/luke/RUK18_Offshore_Timeline.p df

[21] Miller, R. E., \& Blair, P. D. (2009). Input-Output Analysis. Foundations and Extensions. (Second). Cambridge University Press.

[22] McGregor, P, G., Swales, K., \& Yin, Y. P. (2019). A Long-Run Interpretation of Regional Input Output Analysis Journal of Regional Science, 36, 479-501.

[23] Harrigan, F., McGregor, P. G., Dourmashkin, N., Perman, R., Swales, K., \& Yin, Y. P. (1991). AMOS. A macro-micro model of Scotland. Economic Modelling, 8(4), 424-479.

https://doi.org/10.1016/0264-9993(91)90028-M

[24] Allan, G., Lecca, P., McGregor, P., \& Swales, K. (2014b). The economic and environmental impact of a carbon tax for Scotland: A computable general equilibrium analysis. Ecological Economics , 100, 40-50. https://doi.org/10.1016/j.ecolecon.2014.01.012

[25] Armington, P. (1969). A theory of demand for products distinguished by place of production. IMF Economic Review, 16(1), 159-178. DOI: 10.2307/3866403

[26] Lecca, P., Swales, K., \& Turner, K. (2011). An investigation of issues relating to where energy should enter the production function. Economic Modelling, 28(6), 2832-2841.

https://doi.org/10.1016/j.econmod.2011.08.014 
[27] Jorgenson, Dale, W. (1963). Capital Theory and Investment Behaviour. American Economic Association, 53(2), 247-259. Retrieved from

https://scholar.harvard.edu/jorgenson/publications/capital-theory-and-investment-behavior

[28] Hayashi, F. (1982). Tobin's Marginal q and Average q : A Neoclassical Interpretation. Econometrica, 5O(1), 213-224. DOI: 10.2307/1912538

[29] Higgins, P., \& Foley, A. M. (2013). Review of offshore wind power development in the United Kingdom. 12th International Conference on Environment and Electrical Engineering, EEEIC 2013, 589-593. https://doi.org/10.1109/EEEIC.2013.6549584

[30] Orecca. (2018). UK Annual offshore wind speeds. Retrieved from http://map.rseweb.it/orecca/map.phtml

[31] Crown Estate. (2010). A Guide to an Offshore Wind Farm. Retrieved from http://www.thecrownestate.co.uk/guide to offshore windfarm.pdf

[32] BVG Associates. (2010). Value breakdown for the offshore wind sector. Renewables Advisory Board. Retrieved from

https://www.gov.uk/government/uploads/system/uploads/attachment data/file/48171/2806value-breakdown-offshore-wind-sector.pdf

[33] Mone, C., Hand, M., Bolinger, M., Rand, J., Heimiller, D., \& Ho, J. (2017). 2015 Cost of Wind Energy Review. Nrel, (May). Retrieved from https://www.nrel.gov/docs/fy17osti/66861.pdf

[34] Carroll, J., Mcdonald, A., Dinwoodie, I., Mcmillan, D., Revie, M., \& Lazakis, I. (2017). A Comparison of the Availability and Operation \& Maintenance Costs of Offshore Wind Turbines with Different Drive Train Configurations. Wind Energy, 20(2), 361-378. https://doi.org/10.1002/we.2011

[35] BVG Associates. (2012). UK content analysis of Robin Rigg Offshore Wind Farm operations and maintenance. Retrieved from

https://www.eonenergy.com/ /media/PDFs/Generation/wind/offshore/Eon_Robin_Rigg_OM_repor t.pdf

[36] UK Government. (2019). Offshore wind sector deal. Retrieved from https://www.gov.uk/government/uploads/system/uploads/attachment data/file/643560/CFD alloc ation round 2 outcome FINAL.pdf

[37] Allan, G. J., Comerford, D., Connolly, K., McGregor, P. G., \& Ross, A. G. (2020). The economic and environmental impacts of UK offshore wind development: The importance of local content. Energy 199, forthcoming. https://doi.org/10.1016/j.energy.2020.117436 